\author{
И.В. Конорюкова
}

\title{
Структурное представление субъектных свойств воспитателя дошкольной образовательной организации на этапе адаптации к профессиональной деятельности
}

\begin{abstract}
Аннотация. В рамках поискового научного исследования по выявлению тичностных предпосылок успешности адаптации специалиста к профессиональной деятельности осуществлен профессиографический анализ и смоделирована психограмма воспитателя дошкольной образовательной организации. В статье перечислены концептуально-теоретические приниипы авторского профессиографического подхода к феномену адаптации воспитателей к профессиональной деятельности. Опираясь на наследие А.К. Марковой и Е.А. Климова, автор рассматривает возможности профессионального развития педагогов в контексте осознания личностных конструктов. В иеетре рассмотрения вопросы успешности адаптации, субъектной позиционности и рефлексивности воспитателей. Содержательная рамка описания успешности адаптации воспитателей $\kappa$ профессиональной деятельности формируется с учётом анализа факторов, определяющих трансформаиию пути профессионального становления. Показана роль способности осознания личностных конструктов и ориентации в профессиональной деятельности на самосовершенствование как необходимого базиса для успешного адаптации специалиста. Осуществлённый на основе рефлексивных действий проектный сценарий процесса освоения профессиональной деятельности, позволяет обеспечить условия для осмысления всех сторон труда в контексте профессиональной жизни в соотнесении с психограммной матрицей профессии и, в конечном итоге, приводит к успешному прохождению данного этапа профессионального становления.
\end{abstract}

Ключевые слова: адаптация, профессиональная деятельность, профессионально важные качества, психограмма, контент-анализ, экспертная оценка, личность, успешность адаптации, профессия, трудовые функиии.

Abstract. Within the aim of the research to identify personal prerequisites for successful adaptation of a specialist to professional activities, the author carried out a professional graphic analysis and modeled a mental graph of a preschool teacher. In her article Konoryukova lists conceptual and theoretical principles of her approach to the phenomenon of adaptation of teachers to their professional activity. Based on researches by A. Markova and E. Klimov, the author considers the possibility of professional development of teachers in terms of awareness of personal constructs. The emphasis is made on issues of successful adaptation, subjective positionality and reflexive abilities of educators. Successful adaptation of teachers to professional activity is described based on analysis of factors determining the transformation path of professional development. The author demonstrates the importance of being aware of personality constructs and attitudes to professional activities in the process of self-improvement as a necessary basis for successful adaptation. The draft scenario of the process of acquiring professional skills and knowledge based on reflective actions allows to create conditions for understanding all aspects of labour in terms of a professional profile and, as a result, to successfully complete the aforesaid stage of professional development.

Keywords: labour functions, profession, success of adaptation, personality, expert assessment, content analysis, psychic profile, profesionally important qualities, professional activity, adaptation. 


\section{Педагогика и просвещение 4(24) • 2016}

$\mathrm{B}$ ведение новых нормативныхактов и изменение концептуальных подходов в образовании спровоцировало изменения в структуре и механизме осуществления профессиональной деятельности воспитателей. В связи с этим проблема адаптации молодых воспитателей к профессиональной деятельности приобретает особую актуальность.

Кроме того, значимость вопроса адаптации выпускников представителей данной профессиональной группы, важна в связи с тем, что, согласно запросу образовательной практики, остро стоит проблема дефицита педагогических кадров в системе дошкольного образования и низкой востребованности данной профессии среди молодёжи, с одной стороны, и недостаточной разработанностью проблемы сохранения кадрового потенциала в дошкольной образовательной организации через систему мероприятий, направленную на психологическое, организационное, методическое сопровождение адаптации воспитателей в теоретическом аспекте, с другой стороны. Следует отметить, что научные исследования в области изучения «адаптации воспитателя к профессиональной деятельности» составляют всего 5,06\% от общего количества работ по дошкольному образованию.

На основании систематизации подходов зарубежных и отечественных исследователей относительно вопроса содержания понятия «адаптация к профессиональной деятельности» можно сделать вывод, что определения весьма неоднозначны и противоречивы, что связано с большим количеством подходов и с объективной сложностью самого феномена адаптации.

По нашему мнению, адаптация воспитателя к профессиональной деятельности - это процесс овладения им знаний, умений и навыков, норм и функций профессиональной деятельности, вхождения в ролевую структуру профессиональной группы, формирования профессионально-значимых качеств и соответствующего отношения к профессии и себе как к субъекту данной профессиональной деятельности (Я-концепции профессионала) [1].

Проанализировав междисциплинарные и психологические подходы исследования проблемы оценки успешности адаптации воспитателей к профессиональной деятельности, мы пришли к выводу, что при рассмотрении данного феномена большое значение имеет выявление и учёт личностных качеств специалиста, которые отражаются в характере и направленности профессиональной деятельности. И поэтому именно через призму личности целесообразно рассматривать успешность адаптации молодых педагогов системы дошкольного образования.

Теоретический анализ специальной литературы позволил выявить взаимосвязь между знанием адаптантом психограммы и успешностью овладения профессией. Сопоставление работником того, какими профессиональными и личностными качествами необходимо обладать специалисту, и того, чем располагает он для выполнения требований, предъявляемых к профессиональной компетентности воспитателя, позволяет ему выявить слабые места, пробелы в своей профессиональной подготовке. На основе всего этого создаются предпосылки для усиления профессиональной направленности образовательного процесса. Знание педагогом роли профессионально-педагогических и личностных качеств воспитателя в профессиональной деятельности способствует стремлению каждого педагога к совершенствованию этих качеств, что, в конечном итоге, ведёт к качественным изменениям в образовательном процессе. Психограмма показывает пути самосовершенствования в профессиональной деятельности.

С целью выделения и описания значимых личностных и профессиональных качеств воспитателей для успешной реализации трудовых функций на этапе адаптации к профессиональной деятельности и качеств, негативно сказывающихс на процесс овладения профессией, нами был проведён контент-анализ публикаций из различных источников (книг, диссертаций, специальных изданий, интернет-публикаций) и экспертная оценка с использованием профессиографических опросников [5].

В проведённом нами исследовании приняли участие в качестве респондентов 186 воспитателей детских садов города Твери и Тверской области со стажем работы от 1 до 3 лет.

Результаты эмпирического исследования легли в основу составления психограммы. При разработки психологического «портрета» воспи- 


\section{Структура педагогической науки}

тателя на этапе адаптации к профессиональной деятельности мы опирались на задачно-личностный модульный подход, разработанный А.К. Марковой [2], и эталонную модель ключевых компетентностей педагогического работника, предложенную Региональным научно-методическим центром экспертной оценки педагоги- ческой деятельности ГБОУ ВПО МО «Академией социального управления» [6].

Ниже представим составленную нами психограмму воспитателя ДДо на этапе адаптации к профессиональной деятельности сучётом требований новых нормативных актов, регулирующих их деятельность [3; 4].

\section{Психограмма воспитателя ДД0 на этапе адаптации к профессиональной деятельности}

\section{Первая сторона труда воспитателя на этапе адаптации к профессиональной деятельности: педагогическая деятельность.}

Владение профессиональной деятельностью и способность проектировать своё дальнейшее профессиональное развитие.

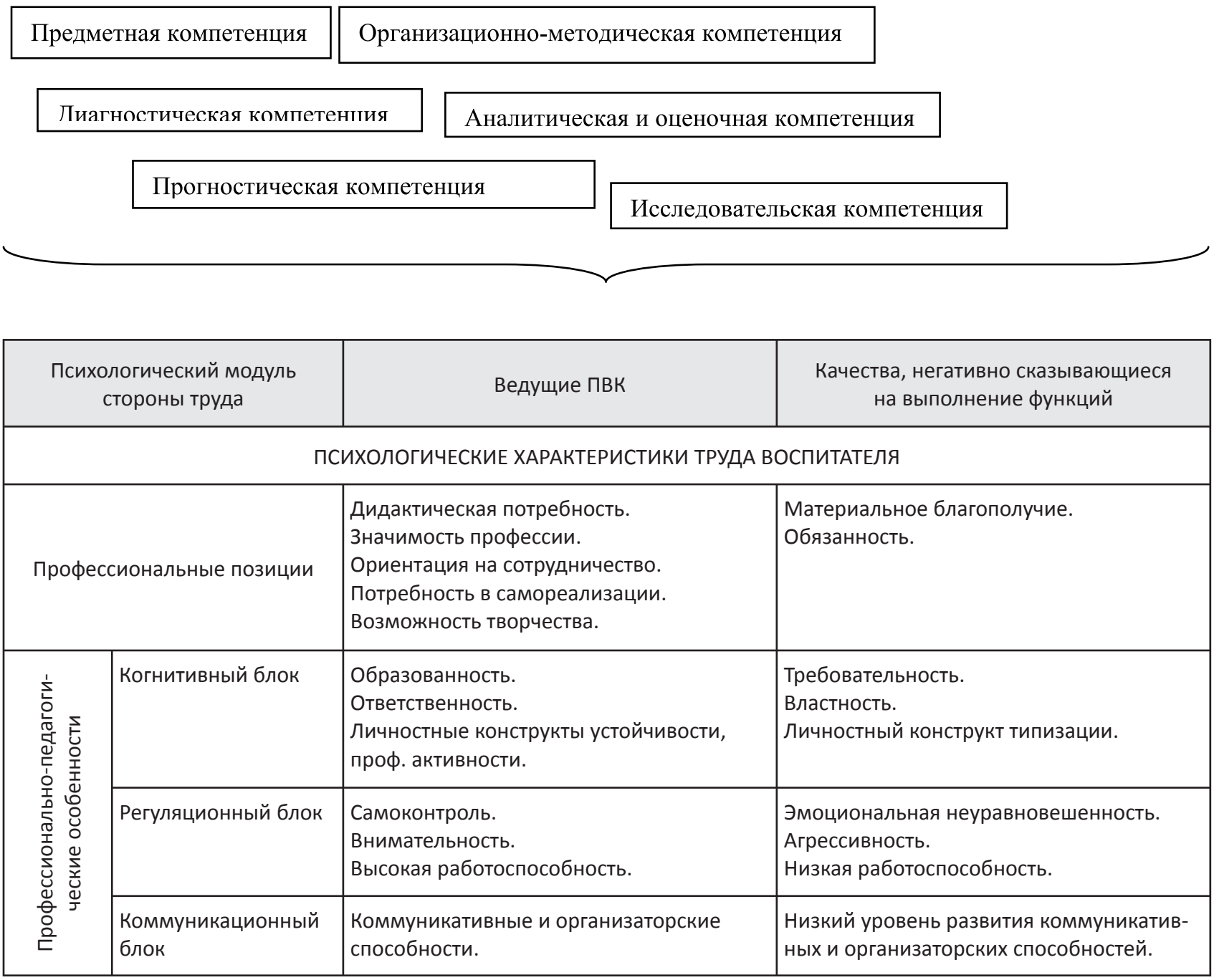




\section{Педагогика и просвещение 4(24) • 2016}

\begin{tabular}{|c|c|}
\hline $\begin{array}{c}\text { Психологический модуль } \\
\text { стороны труда }\end{array}$ & $\begin{array}{c}\text { Качества, негативно сказывающиеся } \\
\text { на выполнение функций }\end{array}$ \\
\hline \multicolumn{2}{|r|}{ ОБЪЕКТИВНО НЕОБХОДИМЫЕ ХАРАТЕРИСТИКИ ТРУДА } \\
\hline Профессиональные знания & $\begin{array}{l}\text { 1. Знать специфику дошкольного образования и особенности организации образова- } \\
\text { тельной работы с детьми раннего и дошкольного возраста [4, с. 14]. } \\
\text { 2. Знать общие закономерности развития ребёнка в раннем и дошкольном детстве; } \\
\text { особенности становления и развития детских деятельностей в раннем и дошкольном } \\
\text { возрасте [4, с. 15]. } \\
\text { 3. Владеть теорией физического, познавательного и личностного развития детей ран- } \\
\text { него и дошкольного возраста [4, с. 15]. } \\
\text { 4. Знать приоритетные направления развития образовательной системы Российской } \\
\text { Федерации; законы и иные нормативные правовые акты, регламентирующие образо- } \\
\text { вательную деятельность [6]. } \\
\text { 5. Знать детскую, возрастную и социальную психологию; психологию отношений, воз- } \\
\text { растную физиологию [2]. } \\
\text { 6. Знать методы управления образовательными системами; современные педагоги- } \\
\text { ческие технологии [2]. } \\
\text { 7. Знать методы и формы мониторинга деятельности воспитанников [2]. }\end{array}$ \\
\hline Профессиональные умения & $\begin{array}{l}\text { 1. Уметь организовывать ведущие в дошкольном возрасте виды деятельности: пред- } \\
\text { метно-манипулятивную и игровую, обеспечивая развитие детей. Организовывать сов- } \\
\text { местную и самостоятельную деятельность дошкольников [4, с. 15]. } \\
\text { 2. Участвовать в создании психологически комфортной и безопасной образовательной } \\
\text { среды, обеспечивая безопасность жизни детей, сохранение и укрепление их здоровья } \\
\text { [4, с. 15]. } \\
\text { 3. Владеть психолого-педагогическими технологиями (в том числе инклюзивными), } \\
\text { необходимыми для работы с различными учащимися: одаренные дети, социально } \\
\text { уязвимые дети, попавшие в трудные жизненные ситуации, дети-мигранты, дети-си- } \\
\text { роты, дети с особыми образовательными потребностями (аутисты, СдВГ и др.), дети с } \\
\text { ОВЗ, дети с девиациями поведения, дети с зависимостью [4, с. 15]. } \\
\text { 4. Владеть педагогическими методиками физического, познавательного и личностного } \\
\text { развития детей раннего и дошкольного возраста [2]. } \\
\text { 5. Уметь строить воспитательную деятельность с учётом культурных различий детей, } \\
\text { половозрастных и индивидуальных особенностей [4, с. 11]. } \\
\text { 6. Способность в ходе наблюдения выявлять разнообразные проблемы детей, связан- } \\
\text { ные с особенностями их развития, оказывать им адресную помощь ребёнку своими } \\
\text { педагогическими приемами. [4, с. 11]. } \\
\text { 7. Уметь планировать, реализовывать и анализировать образовательную работу с } \\
\text { детьми раннего и дошкольного возраста в соответствии с ФгоС дошкольного образо- } \\
\text { вания [3]. } \\
\text { 8. Уметь планировать и корректировать образовательные задачи (совместно с психо- } \\
\text { логом и другими специалистами) по результатам мониторинга, с учетом индивидуаль- } \\
\text { ных особенностей развития каждого ребёнка раннего и/или дошкольного возраста [4, } \\
\text { с. 15]. } \\
\text { 9. Владеть методами и средствами анализа психолого-педагогического мониторинга, } \\
\text { позволяющего оценить результаты освоения детьми образовательных программ, сте- } \\
\text { пень сформированности у них необходимых интегративных качеств детей дошкольно- } \\
\text { го возраста, необходимых для дальнейшего обучения и развития в начальной школе } \\
\text { [4, с. 15]. } \\
\text { 10. Уметь составлять совместно с другими специалистами программу индивидуально- } \\
\text { го развития ребёнка, реализовывать их рекомендации [4, с. 15]. }\end{array}$ \\
\hline
\end{tabular}




\section{Структура педагогической науки}

Владение ИКТ-технологиями.

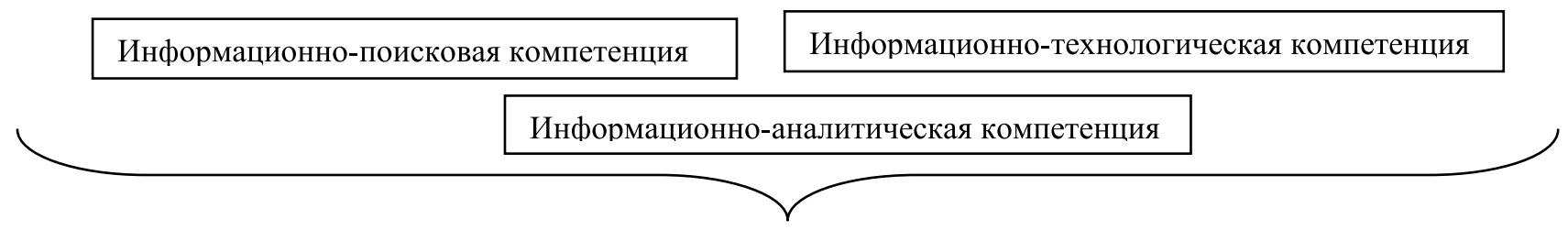

\begin{tabular}{|c|c|c|c|}
\hline \multicolumn{2}{|c|}{$\begin{array}{c}\text { Психологический модуль } \\
\text { стороны труда }\end{array}$} & Ведущие ПВК & $\begin{array}{c}\text { Качества, негативно сказывающиеся } \\
\text { на выполнение функций }\end{array}$ \\
\hline \multicolumn{4}{|c|}{ ПСИХОЛОГИЧЕСКИЕ ХАРАКТЕРИСТИКИ ТРУДА ВОСПИТАТЕЛЯ } \\
\hline \multicolumn{2}{|c|}{ Профессиональные позиции } & $\begin{array}{l}\text { Дидактическая потребность } \\
\text { Организация труда. }\end{array}$ & $\begin{array}{l}\text { Материальное благополучие. } \\
\text { Обязанность. }\end{array}$ \\
\hline \multirow{3}{*}{ 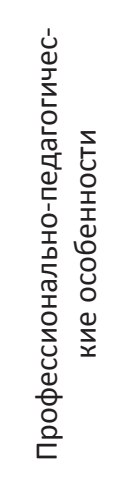 } & Когнитивный блок & $\begin{array}{l}\text { Образованность. } \\
\text { Ответственность. } \\
\text { Личностные конструкты устойчивости, проф. } \\
\text { активности. }\end{array}$ & $\begin{array}{l}\text { Требовательность. } \\
\text { Властность. } \\
\text { Личностный конструкт типизации. }\end{array}$ \\
\hline & Регуляционный блок & $\begin{array}{l}\text { Самоконтроль. } \\
\text { Внимательность. } \\
\text { Высокая работоспособность. }\end{array}$ & $\begin{array}{l}\text { Эмоциональная неуравновешен- } \\
\text { ность. } \\
\text { Агрессивность. } \\
\text { Низкая работоспособность. }\end{array}$ \\
\hline & $\begin{array}{l}\text { Коммуникационный } \\
\text { блок }\end{array}$ & $\begin{array}{l}\text { Коммуникативные и организаторские } \\
\text { способности. }\end{array}$ & $\begin{array}{l}\text { Низкий уровень развития коммуни- } \\
\text { кативных и организаторских способ- } \\
\text { ностей. }\end{array}$ \\
\hline \multicolumn{4}{|c|}{ ОБЪЕКТИВНО НЕОБХОДИМЫЕ ХАРАТЕРИСТИКИ ТРУДА } \\
\hline \multicolumn{2}{|c|}{ Профессиональные знания } & \multicolumn{2}{|c|}{$\begin{array}{l}\text { 1. Знать этические и правовые нормы использования ИКт [4, с. 11]. } \\
\text { 2. Знать ИКТ-технологии, необходимые и достаточные для планирования, реализа- } \\
\text { ции профессиональной деятельности [4, с. 15]. } \\
\text { 3. Знать основы работы с текстовыми редакторами, электронными таблицами, элект- } \\
\text { ронной почтой и браузерами, мультимедийным оборудованием [6]. }\end{array}$} \\
\hline \multicolumn{2}{|c|}{ Профессиональные умения } & \multicolumn{2}{|c|}{$\begin{array}{l}\text { 1. Владеть ИКТ-компетенциями, необходимыми и достаточными для планирования, } \\
\text { реализации профессиональной деятельности [4, с. 15]. } \\
\text { 2. Уметь находить необходимую информацию из различных источников, анализиро- } \\
\text { вать и управлять ею [6]. } \\
\text { 3. Способность пользоваться, воспроизводить, совершенствовать средства и способы } \\
\text { получения и воспроизведения информации в печатном и электронном виде; знание } \\
\text { основных прикладных программ и умение пользоваться ими; навыки работы с ком- } \\
\text { пьютером [6]. }\end{array}$} \\
\hline
\end{tabular}




\section{Педагогика и просвещение 4(24) • 2016}

\section{Вторая сторона труда воспитателя на этапе адаптации к профессиональной деятельности: педагогическое общение.}

Владение нормами профессионального общения, этическими нормами профессии.

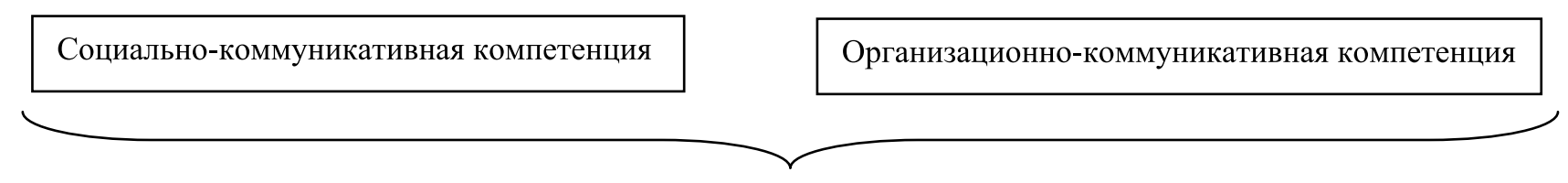

\begin{tabular}{|c|c|c|c|}
\hline \multicolumn{2}{|c|}{$\begin{array}{c}\text { Психологический модуль } \\
\text { стороны труда }\end{array}$} & Ведущие ПВК & $\begin{array}{c}\text { Качества, негативно сказывающиеся } \\
\text { на выполнение функций }\end{array}$ \\
\hline \multicolumn{4}{|c|}{ ПСИХОЛОГИЧЕСКИЕ ХАРАКТЕРИСТИКИ ТРУДА ВОСПИТАТЕЛЯ } \\
\hline \multicolumn{2}{|c|}{ Профессиональные позиции } & $\begin{array}{l}\text { Стремление к самосовершенствованию. } \\
\text { Ориентация на сотрудничество. }\end{array}$ & $\begin{array}{l}\text { Материальное благополучие. } \\
\text { Обязанность. }\end{array}$ \\
\hline \multirow{3}{*}{ 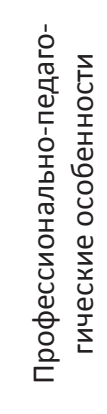 } & $\begin{array}{l}\text { Эмпатия. } \\
\text { Педагогический такт. } \\
\text { Доброжелательность. }\end{array}$ & $\begin{array}{l}\text { Эгоистичность. } \\
\text { Подозрительность. } \\
\text { Властность. }\end{array}$ & $\begin{array}{l}\text { Требовательность. } \\
\text { Властность. } \\
\text { Личностный конструкт типизации. }\end{array}$ \\
\hline & $\begin{array}{l}\text { Самоконтроль. } \\
\text { Внимательность. } \\
\text { Рефлексивность. }\end{array}$ & $\begin{array}{l}\text { Эмоциональная неуравновешенность. } \\
\text { Агрессивность. } \\
\text { Низкая работоспособность. }\end{array}$ & $\begin{array}{l}\text { Эмоциональная неуравновешенность. } \\
\text { Агрессивность. } \\
\text { Низкая работоспособность. }\end{array}$ \\
\hline & $\begin{array}{l}\text { Коммуникативные и } \\
\text { организаторские } \\
\text { способности. }\end{array}$ & $\begin{array}{l}\text { Низкий уровень развития коммуника-тивных, } \\
\text { организаторских способностей. }\end{array}$ & $\begin{array}{l}\text { Низкий уровень развития коммуни- } \\
\text { кативных и организаторских способ- } \\
\text { ностей. }\end{array}$ \\
\hline \multicolumn{4}{|c|}{ ОБЪЕКТИВНО НЕОБХОДИМЫЕ ХАРАТЕРИСТИКИ ТРУДА } \\
\hline \multicolumn{2}{|c|}{ Профессиональные знания } & \multicolumn{2}{|c|}{$\begin{array}{l}\text { 1. Знать педагогическую этику. } \\
\text { 2. Знать методы убеждения, аргументации своей позиции, установления контактов с } \\
\text { обучающимися, воспитанниками разного возраста, их родителями (лицами, их заменя- } \\
\text { ющими), коллегами по работе; технологии диагностики причин конфликтных ситуаций, } \\
\text { их профилактики и разрешения [6]. }\end{array}$} \\
\hline \multicolumn{2}{|c|}{ Профессиональные умения } & \multicolumn{2}{|c|}{$\begin{array}{l}\text { 1. Уметь сотрудничать (конструктивно взаимодействовать) с другими педагогами и спе- } \\
\text { циалистами в решении образовательных задач [4, с. 15]. } \\
\text { 2. Уметь совместно с психологом и другими специалистами осуществлять мониторинг } \\
\text { личностных достижений и составлять психолого-педагогическую характеристику лич- } \\
\text { ности воспитанника }[4, \text { с. } 12] \text {. } \\
\text { 3. Владеть методами и средствами психолого-педагогического просвещения родителей } \\
\text { (законных представителей) детей раннего и дошкольного возраста, уметь выстраивать } \\
\text { партнёрское взаимодействие с ними для решения образовательных задач [4, с. 15]. } \\
\text { 4. Уметь общаться с детьми, признавая их достоинство, понимая и принимая их, защи- } \\
\text { щать достоинство и интересы воспитанников, помогать детям, оказавшимся в конф- } \\
\text { ликтной ситуации и/или неблагоприятных условиях [4, с. 13]. } \\
\text { 5. Уметь поддерживать конструктивные воспитательные усилия родителей (лиц, их } \\
\text { заменяющих) детей, привлекать семью к решению вопросов воспитания ребёнка [4, } \\
\text { с. 13]. }\end{array}$} \\
\hline
\end{tabular}




\section{Структура педагогической науки}

Третья сторона труда воспитателя на этапе адаптации к профессиональной деятельности: личность педагога.

Владение способами личностного самовыражения и саморазвития, средствами противостояния профессиональным деформациям личности; готовность к повышению квалификации и потребность в самопознании, самоактуализации.

\begin{tabular}{|c|c|c|c|}
\hline \multicolumn{2}{|c|}{$\begin{array}{c}\text { Психологический модуль } \\
\text { стороны труда }\end{array}$} & Ведущие ПВК & $\begin{array}{c}\text { Качества, негативно сказывающиеся на } \\
\text { выполнение функций }\end{array}$ \\
\hline \multicolumn{4}{|c|}{ СУБЪЕКТИВНЫЕ (ПСИХОЛОГИЧЕСКИЕ) ХАРАКТЕРИСТИКИ ТРУДА ВОСПИТАТЕЛЯ } \\
\hline \multicolumn{2}{|c|}{ Профессиональные позиции } & $\begin{array}{l}\text { Дидактическая потребность. } \\
\text { Ориентация на сотрудничество. } \\
\text { Значимость профессии. } \\
\text { Возможность повышения квалификации. } \\
\text { Потребность в самореализации. }\end{array}$ & $\begin{array}{l}\text { Материальное благополучие. } \\
\text { Обязанность. }\end{array}$ \\
\hline \multirow{3}{*}{ 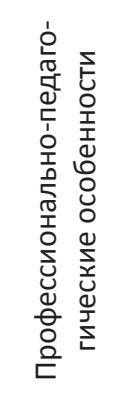 } & Когнитивный блок & $\begin{array}{l}\text { Образованность. } \\
\text { Ответственность. } \\
\text { Личностные конструкты устойчивости, } \\
\text { проф. активности. }\end{array}$ & $\begin{array}{l}\text { Требовательность. } \\
\text { Властность. } \\
\text { Личностный конструкт типизации. }\end{array}$ \\
\hline & Регуляционный блок & $\begin{array}{l}\text { Самоконтроль. } \\
\text { Внимательность. } \\
\text { Высокая работоспособность. }\end{array}$ & $\begin{array}{l}\text { Эмоциональная неуравновешенность. } \\
\text { Агрессивность. } \\
\text { Низкая работоспособность. }\end{array}$ \\
\hline & $\begin{array}{l}\text { Коммуникационный } \\
\text { блок }\end{array}$ & $\begin{array}{l}\text { Коммуникативные и организаторские } \\
\text { способности. }\end{array}$ & $\begin{array}{l}\text { Низкий уровень развития коммуникатив- } \\
\text { ных и организаторских способностей. }\end{array}$ \\
\hline \multicolumn{4}{|c|}{ ОБЪЕКТИВНО НЕОБХОДИМЫЕ ХАРАТЕРИСТИКИ ТРУДА } \\
\hline \multicolumn{2}{|c|}{ Профессиональные знания } & \multicolumn{2}{|c|}{$\begin{array}{l}\text { 1. Знать психологию труда, инженерную психологию, эргономику. } \\
\text { 2. Знать приёмы самореализации и развития индивидуальности в рамках профессии. }\end{array}$} \\
\hline \multicolumn{2}{|c|}{ Профессиональные умения } & \multicolumn{2}{|c|}{$\begin{array}{l}\text { Владеть приёмами самореализации и развития индивидуальности в рамках профес- } \\
\text { сии, готовность к профессиональному росту, способность к индивидуальному самосо- } \\
\text { хранению [6]. }\end{array}$} \\
\hline
\end{tabular}

Данная психограмма отражает последние тенденции в образовании и трудовой сфере: внедрение образовательных и профессиональных стандартов, изменения принципов взаимодействия субъектов образовательного процесса и инновационные тенденции. Также в ней отражены все механизмы реализации профессиональной деятельности воспитателя на этапе адаптации и выделены соответствующие личностные и профессиональные качества. Подробное рассмотрение данной профессии и раскрытие её содержания позволяет решить проблему прогнозирования успешности адаптации воспитателей к профессиональной деятельности.

Кроме того, использование психограммы в работе педагога-психолога в качестве диагностического инструментария для анализа психологического «портрета» воспитателя позволит выявить возможные затруднения, которые могут возникнуть у адаптанта, и определить приоритеты дальнейшего сопровождения специалиста в процессе освоения им профессиональной деятельности, а это означает, в свою очередь, показ возможных перспектив изменения в самой профессии и определение путей профессионального саморазвития работника дошкольной образовательной организации. 


\section{Педагогика и просвещение 4(24) • 2016}

\section{Список литературы:}

1. Климов Е.А. Психология профессионала. М.: Институт практической психологии; Воронеж: НПО «МОДЭК», 1996. 400 с.

2. Маркова А.К. Психология профессионализма. М.: Просвещение, 1996. 308 с.

3. Приказ Министерства образования РФ от 17.10 .2013 г. № 1155 «Об утверждении федерального государственного образовательного стандарта дошкольного образования». URL: http://www. garant.ru/products/ipo/prime/doc.

4. Приказ Министерства труда и социальной защиты РФ от 18.10.2013 г. № 544н «Об утверждении профессионального стандарта "Учитель (преподавательская деятельность в области дошкольного, начального общего, основного общего, среднего общего образования) (воспитатель, учитель)” (с изменениями от 05.08.2016 г.)». URL: http://docs.cntd.ru/document/.

5. Федотов С.Н., Косорукова В. Контент-анализ публикаций по проблеме адаптации педагогов дошкольных образовательных организаций к профессиональной деятельности // Научные исследования молодых учёных: теоретические и прикладные аспекты: Сб. науч. ст. мат-лов научно-практической конференции студентов и молодых учёных. Тверь: ЦНИТ, 2016.

6. Эталонная модель компетенций педагогических кадров // Методические материалы по организационно-методической, психолого-педагогической поддержке профессионального роста, самореализации педагогов и формированию ключевых компетентностей, профиля компетенций педагогического работника разработаны региональным научно-методическим центром экспертной оценки педагогической деятельности ГБОУ ВПО МО «Академия социального управления». URL: http://new.asou-mo.ru/index.php/en/strukture/2015-12-24.

\section{References (transliterated):}

1. Klimov E.A. Psikhologiya professionala. M.: Institut prakticheskoi psikhologii; Voronezh: NPO «MODEK», 1996. $400 \mathrm{~s}$.

2. Markova A.K. Psikhologiya professionalizma. M.: Prosveshchenie, 1996. 308 s.

3. Prikaz Ministerstva obrazovaniya RF ot 17.10 .2013 g. № 1155 «Ob utverzhdenii federal'nogo gosudarstvennogo obrazovatel'nogo standarta doshkol'nogo obrazovaniya». URL: http://www.garant. ru/products/ipo/prime/doc.

4. Prikaz Ministerstva truda i sotsial'noi zashchity RF ot 18.10 .2013 g. № $544 \mathrm{n}$ «Ob utverzhdenii professional'nogo standarta “Uchitel' (prepodavatel'skaya deyatel'nost' v oblasti doshkol'nogo, nachal'nogo obshchego, osnovnogo obshchego, srednego obshchego obrazovaniya) (vospitatel', uchitel')" (s izmeneniyami ot 05.08.2016 g.)». URL: http://docs.cntd.ru/document/.

5. Fedotov S.N., Kosorukova V. Kontent-analiz publikatsii po probleme adaptatsii pedagogov doshkol'nykh obrazovatel'nykh organizatsii k professional'noi deyatel'nosti // Nauchnye issledovaniya molodykh uchenykh: teoreticheskie i prikladnye aspekty: Sb. nauch. st. mat-lov nauchno-prakticheskoi konferentsii studentov i molodykh uchenykh. Tver': TsNIT, 2016.

6. Etalonnaya model' kompetentsii pedagogicheskikh kadrov // Metodicheskie materialy po organizatsionno-metodicheskoi, psikhologo-pedagogicheskoi podderzhke professional'nogo rosta, samorealizatsii pedagogov i formirovaniyu klyuchevykh kompetentnostei, profilya kompetentsii pedagogicheskogo rabotnika razrabotany regional'nym nauchno-metodicheskim tsentrom ekspertnoi otsenki pedagogicheskoi deyatel'nosti GBOU VPO MO «Akademiya sotsial'nogo upravleniya». URL: http://new.asou-mo.ru/index.php/en/strukture/2015-12-24. 